nephron

Practice
Nephron 2015;129:6-15

DOI: $10.1159 / 000369308$
Received: August 21, 2014

Accepted after revision: October 24, 2014 Published online: December 18, 2014

\title{
The Effects of Kidney Transplantation on Sleep, Melatonin, Circadian Rhythm and Quality of Life in Kidney Transplant Recipients and Living Donors
}

\author{
Marije Russcher $^{\mathrm{a}} \quad$ J. Elsbeth Nagtegaal ${ }^{\mathrm{a}} \quad$ S. Azam Nurmohamed ${ }^{\mathrm{b}}$ \\ Birgit C.P. Koch ${ }^{c}$ Monique M.L. van der Westerlaken ${ }^{a}$ Eus J.W. van Someren ${ }^{\text {d, e }}$ \\ Stephan J.L. Bakker ${ }^{f}$ Pieter M. ter Wee ${ }^{b}$ Carlo A.J.M. Gaillard ${ }^{f}$ \\ ${ }^{a}$ Department of Hospital Pharmacy, Meander Medical Center, Amersfoort, ${ }^{b}$ Department of Nephrology and \\ ICaR-VU, VU University Medical Center, Amsterdam, ' Department of Hospital Pharmacy, Erasmus Medical \\ Center, Rotterdam, d Department of Sleep and Cognition, Netherlands Institute for Neuroscience, Amsterdam, \\ e Departments of Integrative Neurophysiology and Medical Psychology, VU University and Medical Center, \\ Amsterdam, and fDepartment of Nephrology, University Medical Center Groningen, University of Groningen, \\ Groningen, The Netherlands
}

\section{Key Words}

Circadian rhythm · Kidney transplantation · Melatonin ·

Quality of life · Sleep

\begin{abstract}
Background: Sleep disturbance is an important medical problem in patients with end-stage renal disease. It might be related to the disruption of the body's circadian clock since nocturnal levels of its key biomarker melatonin are markedly reduced. We aimed at investigating whether a change in renal function due to kidney transplantation or donation would modify sleep, melatonin levels, circadian rhythmicity, and quality of life in kidney transplant recipients (KTR) and living donors (LD). Methods: In KTR, we assessed saliva melatonin concentrations, sleep quality and daytime sleepiness prior to and at 2 weeks and 3 months after transplantation. In LD, we assessed these parameters prior to and at 3 months after donation. We additionally assessed 24 -hour core body temperature (CBT), 24-hour blood pressure profile, and quality of life (QoL) prior to and 3 months after transplantation.
\end{abstract}

\begin{tabular}{ll}
\hline Abbreviations used in this article \\
\hline APD & automated peritoneal dialysis \\
AUC & area under the curve \\
CAPD & continuous ambulatory peritoneal dialysis \\
cBT & core body temperature \\
CKD & chronic kidney disease \\
CRIKT & Circadian Rhythm In Kidney Transplantation \\
DLMO & dim light melatonin onset \\
eGFR & estimated glomerular filtration rate \\
ES & effect size \\
ESRD & end-stage renal disease \\
ESS & Epworth Sleepiness Scale \\
KTR & kidney transplant recipient \\
LD & living donor \\
NTR & Netherlands Trial Registry \\
QoL & quality of life \\
RRT & renal replacement therapy \\
SE & sleep efficiency \\
SOL & sleep onset latency \\
TST & total sleep time \\
Tx & transplantation \\
WASO & wake time after sleep onset \\
\end{tabular}

\section{KARGER}

E-Mail karger@karger.com

www.karger.com/nef
(C) 2014 S. Karger AG, Basel

$1660-8151 / 14 / 1291-0006 \$ 39.50 / 0$
Marije Russcher, PharmD

GGz Centraal, Hospital Pharmacy

Utrechtseweg 266

NL-3818 EW Amersfoort (The Netherlands)

E-Mail m.russcher@ggzcentraal.nl 
Results: Twenty-three KTR and 23 LD completed the study. Regarding sleep, the amount of nighttime awake minutes tended to be reduced in recipients after transplantation $(p=$ 0.05). Nocturnal melatonin concentrations did not change with transplantation or donation. Blood pressure dipping profile and the two circadian markers dim-light melatonin onset and time of core body temperature minimum did not change. Nevertheless, KTR reported that daytime sleepiness and QoL had improved. Conclusion: Objectively nocturnal sleep quality marginally improved after transplantation. Subjectively patients reported improved QoL and daytime sleepiness scores. Changes in renal function were not associated with modified melatonin secretion or circadian rhythmicity.

c 2014 S. Karger AG, Basel

\section{Introduction}

Disturbed sleep is highly prevalent in patients with end-stage renal disease (ESRD) and is an important determinant of low quality of life [1-5]. In addition to its effect on psychological well-being, short sleep duration is also associated with increased physical morbidity and mortality [6]. It has been suggested that sleep disturbances represent a risk factor for decline of renal function by promoting hypertension, type 2 diabetes mellitus, and obesity in patients with CKD [7].

Melatonin plays an important role in the sleep wake rhythm, especially in the timing of sleep. This pineal hormone is an important clock-hand of the circadian clock [8]. Its secretion shows a clear circadian rhythm with low levels during the day and high levels at night. It provides a nighttime signal to the body. Its increase in the evening correlates with sleep propensity and onset of sleep [9-11]. In ESRD not only do sleep disturbances frequently occur, but nocturnal melatonin levels are also reduced [12-15]. Even though sleep disturbances in renal patients are well recognized clinically, little attention is paid to their possible linkage with lowered melatonin levels or perturbed functioning of the circadian clock. A combination of sleep deprivation with circadian disruption even raises the chances on developing additional morbidity [16].

Regarding circadian rhythmicity, in kidney transplant recipients (KTR) mainly $24 \mathrm{~h}$ blood pressure profiles have been studied. An inadequate fall in nocturnal blood pressure [17] persists after renal transplantation $[18,19]$. This 'non-dipping' profile is associated with impaired nocturnal endogenous melatonin secretion at least in hypertensive patients [20]. However, information on melatonin rhythm around kidney transplantation is lacking. In a pilot study, we observed an increase in melatonin concentrations after kidney transplantation in 4 out of 7 transplant recipients [21].

In contrast to transplant recipients, living kidney donors experience an abrupt loss of GFR directly after unilateral nephrectomy. The effects of this sudden decline in renal function on sleep and melatonin concentrations are unknown. A gradual decrease in renal function is associated with reduced nocturnal melatonin levels [14]. We questioned whether a sudden decrease in renal function would also lead to reduced melatonin levels. For kidney donors, again, only the circadian rhythm of blood pressure has been studied. Goto et al. found that with unilateral nephrectomy circadian rhythm of blood pressure was disturbed as a function of GFR loss [22].

In the present study, we aimed to expand on our pilot study and investigate whether changes in renal function occurring in KTR and living donors (LD) would subsequently alter melatonin concentrations and sleep quality in conjunction. Since sleep quality is an important determinant of well-being in patients with ESRD, we also measured changes in the quality of life. An additional investigation of the functioning of the circadian clock was done by measuring circadian rhythms of core body temperature and 24-hour blood pressure before and after renal transplantation and donation.

\section{Patients and Methods}

The Circadian Rhythm In Kidney Transplantation (CRIKT) study is a prospective observational longitudinal study conducted at the VU University Medical Centre (VUmc), the Netherlands from April 2011 to October 2013. The institutional review board approved the protocol of the study (NTR2974) and written informed consent was obtained from all participants prior to their inclusion in the study. The study was conducted according to the Declaration of Helsinki.

\section{Setting and Participants}

Kidney transplant recipients and donors, all from the living donation program, aged 18-85 years were eligible for inclusion. Participants were excluded in case of hypnotic or melatonin use, severe psychological or neurological disease, blindness, NYHA class IV heart failure, documented sleep apnea and alcohol or drug abuse.

\section{Outcome Measures}

Melatonin Rhythm

Melatonin concentrations in saliva were measured at baseline, approximately 1 month before transplantation (KTR and LD), 2 weeks after transplantation (KTR only), and 3 months after transplantation (KTR and LD). Saliva was sampled at 19:00, 21:00, 
23:00, 01:00 and 07:00. Saliva samples were collected and melatonin concentrations were determined as described before [23]. Values below the detection limit of $0.5 \mathrm{pg} / \mathrm{ml}$ were set at $0 \mathrm{pg} / \mathrm{ml}$ for further calculation.

\section{Sleep Measurement}

Sleep parameters were investigated with actigraphy. This established sleep-monitoring method records wrist movements and automatically discriminates rest-activity patterns interpreted in terms of sleep and wake periods [24]. Model Actiwatch 2 (Respironics Inc., Murrysville, Pa., USA) was used. Participants recorded bedtimes and rise times on a registration form. Respironics Actiware version 5.59 was used to score 1 min epochs of actigraphic data as sleep or wake. The following parameters were calculated by the software: sleep onset latency (SOL), which is the time period between 'lights off and sleep onset, sleep efficiency (SE), which is the sleep time divided by time in bed and is a well-recognized measure of sleep quality, total sleep time (TST), defined as the total duration of sleep periods and wake after sleep onset (WASO), defined as the amount of nighttime awake minutes after sleep onset and before final awakening. Each episode of actigraphy recordings was carried out during 4 consecutive days and nights. Participants performed 3 measurements: at baseline, 2 weeks (KTR only), and 3 months after transplantation.

Daytime Sleepiness

Daytime sleepiness was scored with the Epworth Sleepiness Scale (ESS) questionnaire at baseline (KTR and LD), 2 weeks after transplantation (KTR only), and 3 months after transplantation (KTR and LD). It has been used in ESRD patients previously [5]. A score $>9$ indicates elevated daytime sleepiness.

Quality of Life Questionnaire

Quality of life scores were measured with the Dutch version of the Medical Outcomes Study Short Form 36 (MOS SF-36) at baseline and 3 months after transplantation. This validated questionnaire measures physical, functional, mental, and social health [25].

Ambulatory Blood Pressure

Participants wore an ambulatory blood pressure monitor (SpaceLabs ${ }^{\circledR}$ model 90207 ItéMedical, Tiel, The Netherlands) for $24 \mathrm{~h}$ at baseline and 3 months after transplantation. Measurements were taken every $15 \mathrm{~min}$ between 8:00 and 23:00 and every $30 \mathrm{~min}$ between 23:00 and 8:00. Subjects were allowed to follow their normal daily routine. They were instructed to remain motionless for each blood pressure reading. Dipping status was defined as a decrease in the mean systolic blood pressure of at least $10 \%$ at night compared to daytime [26]. Dipping profile was calculated from the mean systolic values of fixed clock time periods ranging from 10:00 to 20:00 (day) and from 0:00 to 6:00 (night).

\section{Core Body Temperature}

Core body temperature was measured at baseline and 3 months after transplantation with a Jonah capsule ${ }^{\circledR}$ (Respironics, Bend, Oreg., USA). This ingestible disposable capsule contains a temperature sensor that telemetrically transmits information to a monitor, which has to stay $<0.5 \mathrm{~m}$ from the ingested capsule. Transmissions begin $\sim 1$ min after activation and are repeated approximately every minute thereafter. As only intestinal position- ing of the capsule provides valid data, the first $2 \mathrm{~h}$ of data collection were deleted [27]. In addition, all temperatures below $35^{\circ} \mathrm{C}$ and above $40^{\circ} \mathrm{C}$ were discarded, since they were believed to be caused by external factors such as hot or cold drinks.

\section{Statistical Analysis and Parameter Estimates}

Based on our previous pilot data, the primary outcome measure was defined as a mean increase in nocturnal melatonin concentrations of $8.0 \mathrm{pg} / \mathrm{ml}$ after kidney transplantation. A sample size of 27 patients per group was needed based on a power of 0.90 , $\alpha$ of 0.05 , and assumed standard deviation of $9.0 \mathrm{pg} /$ $\mathrm{ml}[21]$.

Mean values and standard deviations of patient characteristics, melatonin concentrations, actigraphy, ESS, quality of life, and blood pressure were calculated. Sleep onset latency was non-normally distributed; therefore, median [interquartile range] results are reported. Melatonin concentrations and blood pressures were plotted. The area under the melatonin curve (AUC) was calculated from 19:00 to 7:00 after linear interpolation between two consecutive data points.

Differences in mean melatonin concentrations, melatonin AUC, actigraphy, ESS, and quality-of-life scores between pre- and post-transplantation were calculated with paired samples $t$ test for recipients and donors separately. In a post-hoc analysis on open versus laparoscopic nephrectomy, quality-of-life results were also compared with paired samples t test. To estimate the clinical relevance of changes in quality-of-life scores, effect sizes (ES) were calculated. Effect sizes are used to relate the magnitude of the effects on the various parameters to their clinical meaningfulness. It expresses the change in the mean in terms of variation in the population. Accepted guidelines for the magnitude of the effect size, $\mathrm{ES}=0.20, \mathrm{ES}=0.50$, and $\mathrm{ES}=0.80$, indicate small, moderate, and large effects respectively [28].

Dim light melatonin onset (DLMO) (a circadian phase marker) was defined as the time that the salivary melatonin concentrations hit the threshold of $2.5 \mathrm{pg} / \mathrm{ml}$ in the ascending limb of the curve with linear interpolation between the point immediately below and above the threshold [29].

Temperature curves were fitted with a linearly detrended twoharmonic $(24+12 \mathrm{~h})$ cosine function. The clock time of the minimum of the fitted curve was used as indicator of the phase of the 24 -hour rhythm in core body temperature [30,31]. Correlations between time of body temperature minimum and DLMO as well as between renal function and melatonin, sleep and quality-of-life parameters were calculated with the Spearman's rank correlation coefficient. Data analysis was done using IBM SPSS 19 (Chicago, Ill., USA).

\section{Results}

Twenty-eight recipients and 29 donors were included between April 2011 and July 2013. Twenty-three recipients and 23 donors completed the study. The study profile, including reasons for loss to follow-up is summarized in figure 1. Clinical characteristics are listed in table 1 . 
Fig. 1. Study profile.

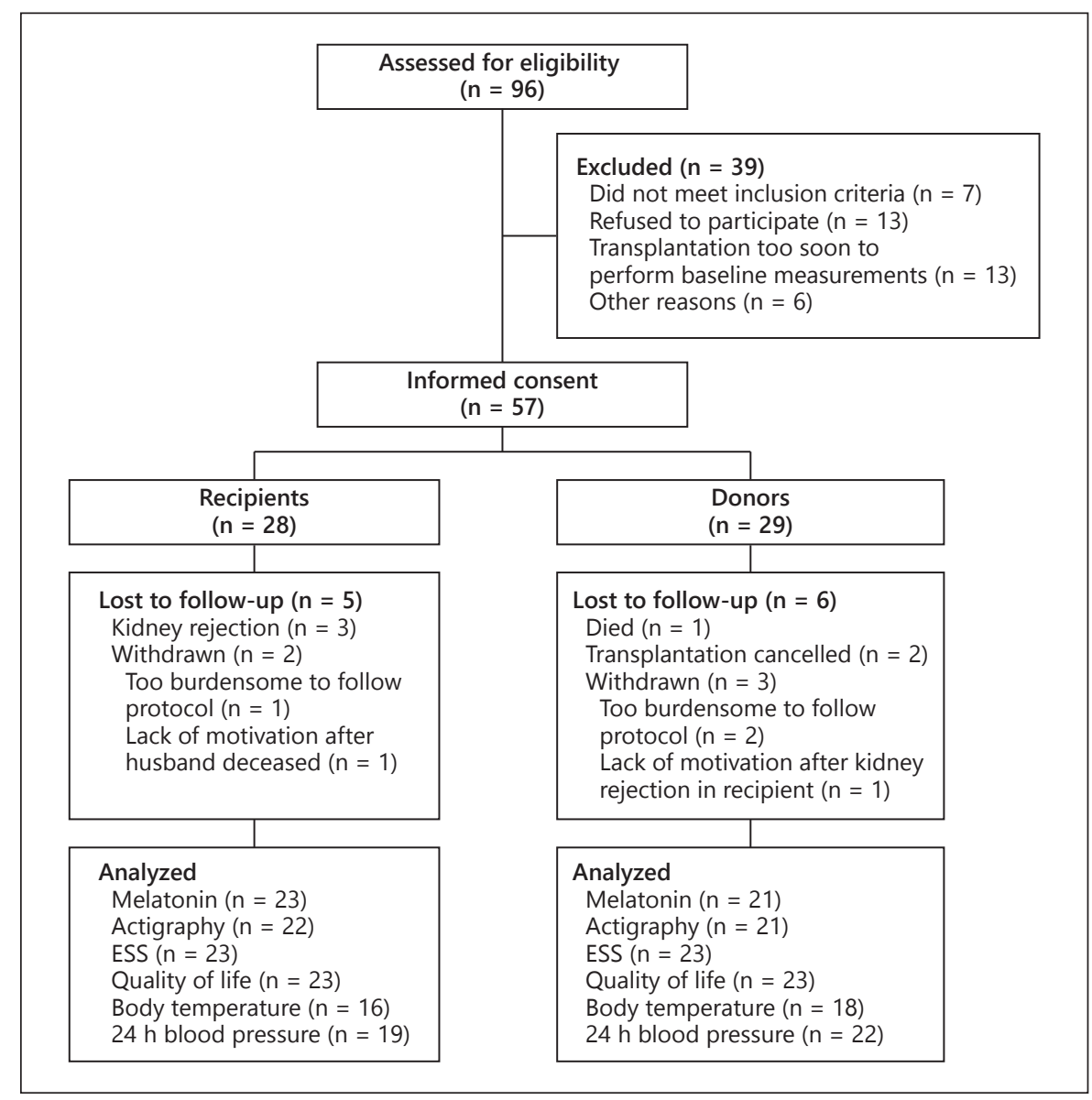

\section{Melatonin Rhythm}

Figures $2 \mathrm{a}$ and $\mathrm{c}$ show salivary melatonin concentrations before and after transplantation and donation. Within both donors and recipients, none of the mean melatonin concentrations differed significantly between pre- and post-Tx except for donors post-Tx mean melatonin concentration at $11 \mathrm{p} . \mathrm{m}$. was higher than the mean pre-transplantation concentration: $5.6 \pm 4.3$ versus $4.1 \pm$ $3.1 \mathrm{pg} / \mathrm{ml}$, respectively, $\mathrm{p}=0.04$. Mean melatonin AUCs pre- and post-surgery did not differ significantly for either KTR or LD. Mean melatonin AUCs for KTR were $44.6 \pm 34.1$ and $49.2 \pm 46.1 \mathrm{pg} \cdot \mathrm{h} / \mathrm{ml}$ at baseline and 3 months after transplantation respectively, $\mathrm{p}=0.44$. Mean melatonin AUCs for LD were $58.9 \pm 34.4$ and $72.7 \pm$ $43.9 \mathrm{pg} \cdot \mathrm{h} / \mathrm{ml}$ at baseline and 3 months after transplantation respectively, $\mathrm{p}=0.06$. Intra-individual concentration time curves of melatonin before and after transplantation were visually examined. Neither concentrations at any of the time points nor areas under the curve (AUC) differed pre- versus post-Tx on an individual level [data not shown]. No significant correlations were found between renal function pre-Tx or post-Tx with melatonin concentrations at 19:00, 21:00, 23:00, 01:00, 07:00 or melatonin AUC for both KTRs and LDs. In addition, no significant correlations between change in renal function and change in melatonin AUC for both KTRs and LDs were found.

\section{Actigraphy and Daytime Sleepiness}

The results of the actigraphy measurements and ESS scores are summarized in table 2 . Pre-Tx, significant correlations between renal function and sleep efficiency $(r=0.513$, $\mathrm{p}=0.015)$ and WASO $(\mathrm{r}=-0.455, \mathrm{p}=0.033)$ were found. Renal function pre-Tx tended to be correlated with sleep onset latency $(\mathrm{r}=-0.380, \mathrm{p}=0.081)$. After transplantation, mean WASO in KTR tended to be reduced from 79.1 to $64.7 \mathrm{~min}, \mathrm{p}=0.051$, at 3 months after transplantation. Sleep onset latency (SOL), total sleep time (TST), and sleep efficiency (SE) did not change significantly after transplantation. For LD, none of the four sleep parameters changed significantly with donation. No significant correlations be- 
Table 1. Characteristics of donors and recipients

\begin{tabular}{|c|c|c|}
\hline & Donors & Recipients \\
\hline Male/female & $17 / 12$ & $18 / 10$ \\
\hline Age, years & $54.9 \pm 13.3$ & $51.0 \pm 13.0$ \\
\hline Body mass index, $\mathrm{kg} / \mathrm{m}^{2}$ & $24.9 \pm 3.1$ & $25.0 \pm 4.13$ \\
\hline \multicolumn{3}{|l|}{ RRT before transplantation } \\
\hline Daytime hemodialysis & n.a. & 7 \\
\hline Nocturnal hemodialysis & n.a. & 1 \\
\hline CAPD & n.a. & 1 \\
\hline APD & n.a. & 1 \\
\hline No RRT & n.a. & 18 \\
\hline \multicolumn{3}{|l|}{ Type of nephrectomy } \\
\hline Laparoscopic & 14 & n.a. \\
\hline Open & 13 & n.a. \\
\hline \multicolumn{3}{|l|}{ Creatinine, $\mu \mathrm{mol} / \mathrm{l}$} \\
\hline Baseline & $72.7 \pm 14.7$ & $499.1 \pm 193.7$ \\
\hline 2 weeks post-Tx & & $130.6 \pm 41.7$ \\
\hline 3 months post- $\mathrm{Tx}$ & $110.6 \pm 22.5$ & $120.7 \pm 28.4$ \\
\hline \multicolumn{3}{|l|}{$\mathrm{eGFR}^{\mathrm{a}}, \mathrm{ml} / \mathrm{min} / 1.73 \mathrm{~m}^{2}$} \\
\hline Baseline & $93.9 \pm 16.0$ & $10.9 \pm 3.2^{\mathrm{b}}$ \\
\hline 2 weeks post-Tx & & $54.1 \pm 17.1$ \\
\hline 3 months post- $\mathrm{Tx}$ & $60.5 \pm 15.8$ & $56.3 \pm 11.8$ \\
\hline Smoking & 6 & 3 \\
\hline Diabetes mellitus at baseline & 0 & 2 \\
\hline$\beta$-blocker usage & 1 & 15 \\
\hline \multicolumn{3}{|l|}{ Alcohol } \\
\hline None & 5 & 9 \\
\hline$<1$ unit/day & 8 & 13 \\
\hline 1-3 units/day & 14 & 5 \\
\hline$>3$ units/day & 2 & 1 \\
\hline
\end{tabular}

Data are expressed as mean \pm SD or number of patients where appropriate.

n.a. $=$ Not applicable RRT $=$ renal replacement therapy CAPD $=$ continuous ambulatory peritoneal dialysis; $\mathrm{APD}=$ automated peritoneal dialysis; eGFR = estimated glomerular filtration rate.

a Calculated by the CKD-EPI formula, http://mdrd.com, accessed on December 10th 2013.

b Calculated for no RRT recipients only.

tween change in renal function and changes in sleep parameters or ESS scores were found for both KTRs and LDs.

Daytime sleepiness scores for KTRs were within the normal range both before and after transplantation, but had significantly decreased at 3 months after transplantation compared to baseline. For LD, daytime sleepiness scores had not changed significantly after donation.

\section{Quality of Life}

Initial quality-of-life scores and changes in scores and effect sizes are shown in tables $3 \mathrm{a}$ and $\mathrm{b}$. No significant correlations between renal function pre-Tx and quality of life pre-Tx were found for KTRs. For LDs, renal function pre-Tx tended to correlate with general health perception $(r=0.439, p=0.053)$. For KTR, there was a significant increase in social functioning, role activitiesphysical, vitality, general health perception and last year's health change between baseline and 3 months post transplantation. For LD, there was a significant worsening of social functioning, role activities-physical, role activitiesemotional, vitality, and pain scores 3 months after donation. Using accepted guidelines for the magnitude of the effect sizes [28], for KTR there was a large positive impact of transplantation on health change, general health perception and vitality, a substantial impact on social functioning, physical role activities and physical functioning, and a small positive effect on emotional role activities. Within this short time-frame of the study, donors experienced a negative effect on emotional and physical role activities, social functioning, pain, vitality, and physical functioning.

We found no significant correlations between the change in renal function and changes in quality-of-life scores for both KTRs and LDs, except that the change in renal function for KTRs was correlated to a change in physical role-activities $(\mathrm{r}=0.426, \mathrm{p}=0.043)$.

The post-hoc analysis on open versus laparoscopic nephrectomy showed that with both types of surgeries, donors experienced significant worsening of physical role activities. Donors who underwent open nephrectomy experienced significant worsening of emotional role activities and pain compared to baseline. Donors who underwent laparoscopic nephrectomy experienced significant worsening of vitality compared to baseline.

\section{Ambulatory Blood Pressure}

The mean blood pressure values before and after transplantation are shown in figures $2 \mathrm{~b}$ and $\mathrm{d}$. At baseline, 6 of the 19 recipients (32\%) had a dipping pattern. After transplantation, 3 of the dipping patients had switched to a non-dipping profile and 3 of the non-dipping patients had switched to a dipping profile. Of the 22 donors, 14 persons (64\%) had a dipping profile at baseline. After transplantation, 5 of the dipping donors had switched to a non-dipping profile and 4 of the non-dipping donors had switched to a dipping profile.

\section{Circadian Parameters: Core Body Temperature and DLMO}

In table 4 , the mean values of the circadian phase markers - clock time of the core body temperature (cBT), minimum and dim light melatonin onset (DLMO) - are 


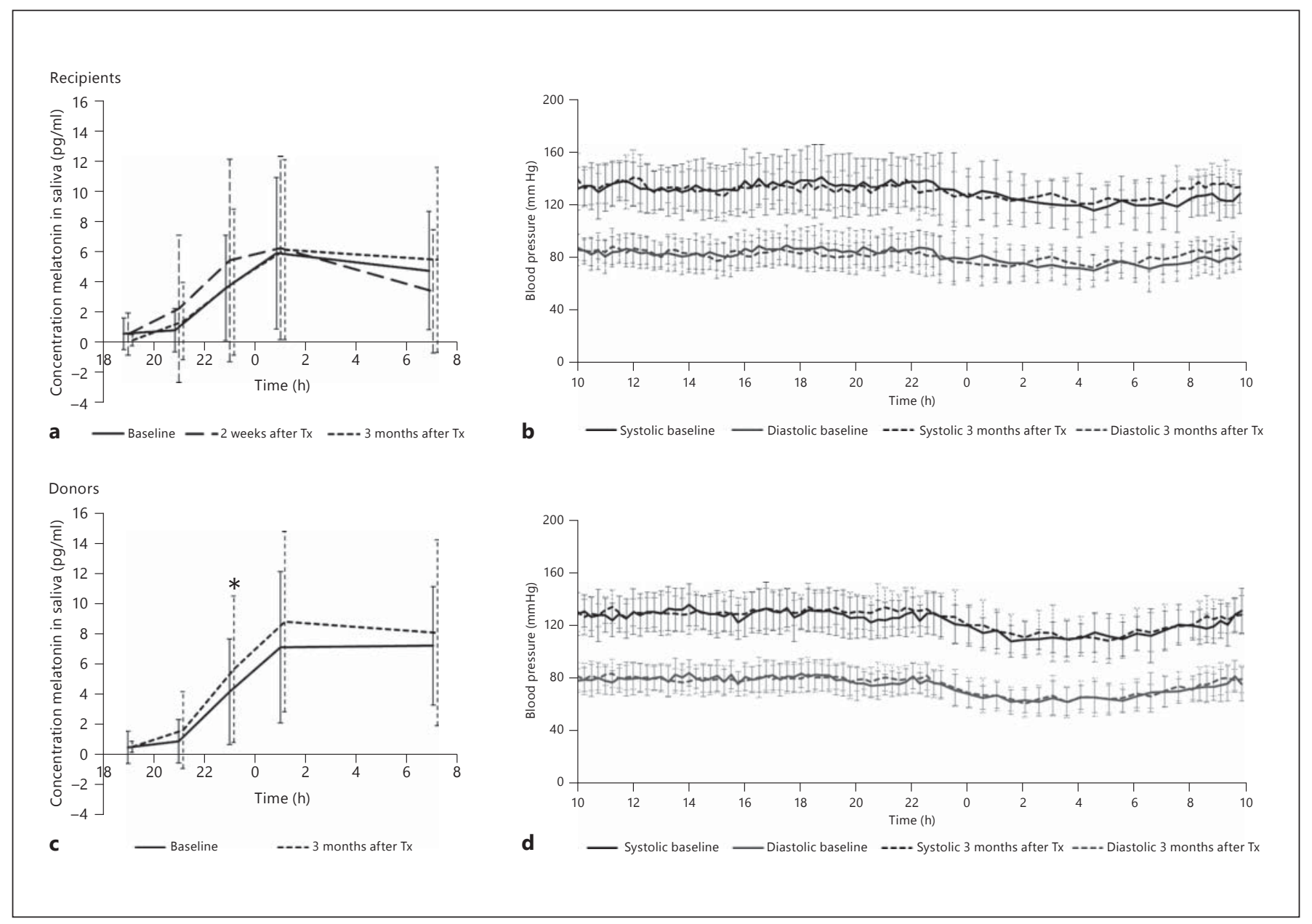

Fig. 2. Melatonin and ambulatory blood pressure results of kidney transplant recipients (upper panels) and donors (lower panels). a, c: Mean \pm SD melatonin concentrations in saliva. The horizontal axis reflects the time of day in hours and the vertical axis reflects the melatonin concentration in saliva in $\mathrm{pg} / \mathrm{ml}$. The solid line represents baseline values, the dashed line represents measurements
2 weeks after transplantation, the dotted line represents measurements 3 months after transplantation. $\mathbf{b}$, d: Mean \pm SD ambulatory blood pressure measurements. Solid lines represent baseline values, dotted lines represent values 3 months after transplantation (Tx). Black lines and grey lines indicate systolic and diastolic values respectively. ${ }^{*} \mathrm{p}<0.05$. listed. For KTR, the results for both cBT and DLMO were not significantly different before and after transplantation. There was no significant correlation between time of temperature minimum and DLMO within the recipients both before and after transplantation $(\mathrm{r}=0.27, \mathrm{p}=$ 0.37 and $\mathrm{r}=0.07, \mathrm{p}=0.86$, respectively). Also for $\mathrm{LD}$, the results for both $\mathrm{CBT}$ and DLMO were not significantly different before and after transplantation. However, before donation, there was a significant correlation between time of temperature minimum and DLMO within the donors. After donation, this correlation within the donors had disappeared (coefficient $=0.61, \mathrm{p}=0.017$ and $\mathrm{r}=0.11$, $\mathrm{p}=0.73$, respectively).

Circadian Rhythm in Kidney

Transplantation

\section{Discussion}

As expected, in renal patients prior to transplantation, we found a significant relationship between renal function and sleep quality. However, sleep quality did not improve after transplantation, with the exception of the number of nighttime awake minutes. In contrast to our hypothesis, after renal transplantation, melatonin concentrations did not improve in KTR, despite marked improvement in the renal function. Mean AUC nor melatonin concentrations changed significantly. In addition, individual melatonin concentration profiles remained remarkably stable throughout the study period. Post transplantation, we did 
Table 2. Actigraphy and daytime sleepiness results for recipients $(n=22)$ and donors $(n=21)$

\begin{tabular}{|c|c|c|c|c|c|c|c|c|c|c|}
\hline & $\begin{array}{l}\text { SOL, } \\
\min \end{array}$ & $\begin{array}{l}\mathrm{p} \\
\text { value* }^{*}\end{array}$ & $\begin{array}{l}\text { TST } \\
\mathrm{h}\end{array}$ & $\begin{array}{l}\mathrm{p} \\
\text { value* }\end{array}$ & SE, \% & $\begin{array}{l}\mathrm{p} \\
\text { value* }^{*}\end{array}$ & $\begin{array}{l}\text { WASO, } \\
\min \end{array}$ & $\begin{array}{l}\mathrm{p} \\
\text { value }^{\mathrm{a}}\end{array}$ & $\begin{array}{l}\text { ESS } \\
\text { score }\end{array}$ & $\begin{array}{l}\mathrm{p} \\
\text { value }^{*}\end{array}$ \\
\hline $\begin{array}{l}\text { Normal values } \\
\text { Recipients }\end{array}$ & $<15$ & & $>5.8$ & & $>85$ & & unknown & & $<9$ & \\
\hline $\begin{array}{l}\text { Baseline } \\
2 \text { weeks after }\end{array}$ & $11.0(5.69-19.69)$ & - & $6.5 \pm 1.0$ & - & $77.8 \pm 12.2$ & - & $79.1 \pm 38.8$ & - & $7.7 \pm 3.9$ & - \\
\hline $\begin{array}{l}\text { Tx } \\
3 \text { months after }\end{array}$ & $9.75(4.31-16.94)$ & 0.25 & $6.6 \pm 1.1$ & 0.68 & $79.4 \pm 9.2$ & 0.64 & $68.5 \pm 35.8$ & 0.19 & $7.0 \pm 4.8$ & 0.43 \\
\hline $\mathrm{Tx}$ & $13.0(7.19-32.1)$ & 0.76 & $6.6 \pm 0.85$ & 0.50 & $79.2 \pm 9.9$ & 0.58 & $64.7 \pm 26.4$ & 0.05 & $4.7 \pm 3.8$ & 0.001 \\
\hline Donors & & & & & & & & & & \\
\hline $\begin{array}{l}\text { Baseline } \\
3 \text { months after }\end{array}$ & $13.0(6.38-21.5)$ & - & $6.7 \pm 0.83$ & - & $83.5 \pm 4.7$ & - & $50.7 \pm 19.3$ & - & $5.2 \pm 3.2$ & - \\
\hline $\mathrm{Tx}$ & $10.25(5.38-15.25)$ & 0.52 & $6.8 \pm 0.82$ & 0.49 & $83.1 \pm 5.6$ & 0.64 & $51.2 \pm 21.9$ & 0.92 & $5.5 \pm 3.2$ & 0.54 \\
\hline
\end{tabular}

Data for SOL are expressed as median (interquartile range), data for TST, SE and WASO are expressed as mean \pm SD.

$\mathrm{SOL}=$ Sleep onset latency (in $\mathrm{min}$ ); TST = total sleep time (in h); SE = sleep efficiency (in \%); WASO = wake after sleep onset (in $\min )$, ESS = Epworth Sleepiness Scale.

* p values calculated versus baseline.

not find significant relationships between (changes in) renal function and (changes in) sleep, melatonin, or quality of life for either KTRs or LDs. However, recipients subjectively experienced less daytime sleepiness as well as major improvements of quality of life after transplantation.

We hypothesized that an increase in renal function would restore melatonin synthesis based on the earlier finding that a decrease in renal function was related to lower nocturnal melatonin concentrations [14] and pilot data showed increased melatonin concentrations in 4 out of 7 transplant recipients [21]. The main ensuing question is why improvement of renal function did not result in increased melatonin levels in this study.

First, our earlier work assessed the effects of a gradual, long-term change in renal function, whereas here melatonin levels were measured relatively shortly after an acute increase in renal function. Apparently, melatonin secretion is not related to improvement of renal function in the short term. Therefore, not glomerular filtration per se, but other long-term, renal function-related mechanisms may be the connection between kidney disease and disturbed melatonin synthesis. At this point, we can only speculate as to the nature of the underlying mechanisms. It has been suggested that the degree of pineal calcification (and therefore the size of remaining uncalcified pineal gland volume) indicates the intra-individual capability to produce melatonin [32]. Indeed, the decrease in melatonin secretion with age is predominantly due to increasing pineal calcification [33]. Although it is unknown whether CKD is associated with calcification of the pineal gland, at least vascular calcification composes a wellknown complication of end-stage renal disease [34].

Second, in this study we found better nocturnal melatonin concentration profiles for KTR at baseline than expected and also sleep was not as disturbed as expected. As a result, we observed only a small, non-significant difference in mean melatonin concentrations and AUCs between donors and recipients, whereas we had expected much lower melatonin concentrations in KTR than in LD based on our earlier findings in hemodialysis patients [15] and recent findings [unpublished data]. In our study, the timing of saliva sampling may have played a role since the nocturnal melatonin peak is expected to occur between 2:00 and 4:00. We did not take samples at these times not wanting to create discomfort to the patients. Possibly, the melatonin peak differences between donors and acceptors would have been larger if nightly samples had been collected between 2 and 4 a.m. [12, 13, 15, 23, 35].

Why did the KTR have relatively high melatonin levels? This could not be explained by a lower rate of $\beta$-blocker usage. Beta-blockers are known to suppress melatonin synthesis. Fifty-four percent of the recipients used $\beta$-blockers. This is equal to the reported $56 \%$ of a previously studied representative hemodialysis population in the Netherlands [36].

Taken together, we submit that our failure to observe improvements of melatonin secretion and the marginal improvement in sleep in KTR is related to the relatively 
Table 3. Quality-of-life results

a In donors and recipients before and 3 months after kidney transplantation

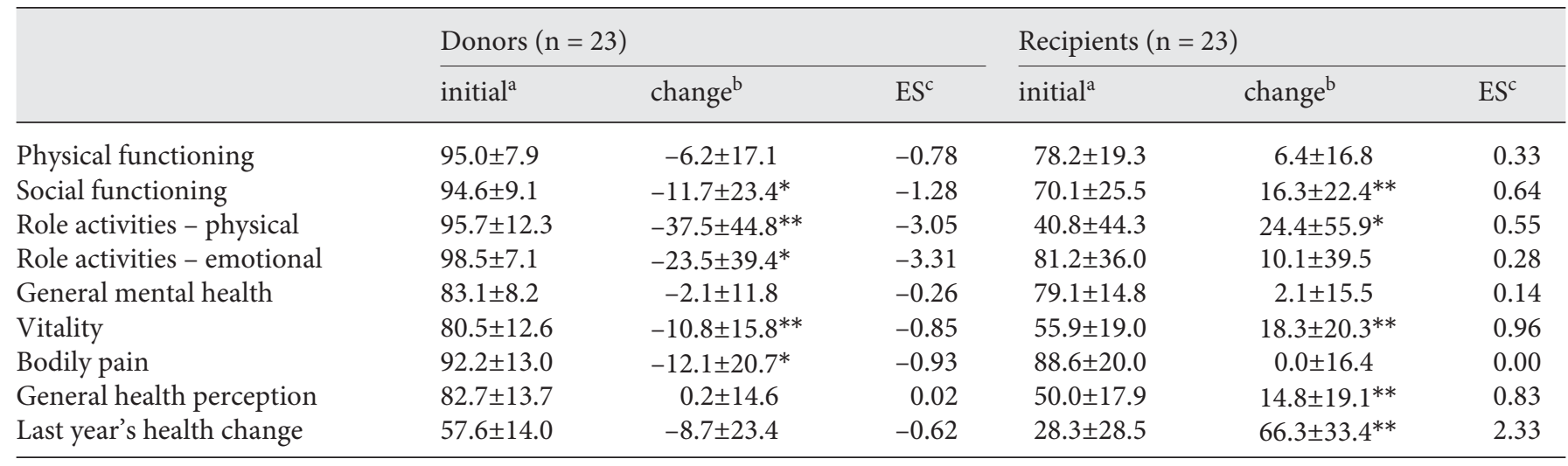

b In donors before and 3 months after kidney donation for open versus laparoscopic nephrectomy

\begin{tabular}{|c|c|c|c|c|c|c|}
\hline & \multicolumn{3}{|c|}{ Open $(n=11)$} & \multicolumn{3}{|c|}{ Laparoscopic $(\mathrm{n}=12)$} \\
\hline Social functioning & $92.0 \pm 10.1$ & $-11.9 \pm 27.4$ & -1.18 & $96.9 \pm 7.8$ & $-11.5 \pm 20.3$ & -1.47 \\
\hline Role activities - physical & $97.7 \pm 7.5$ & $-42.0 \pm 49.5^{*}$ & -5.58 & $93.8 \pm 15.5$ & $-33.3 \pm 41.7^{*}$ & -2.15 \\
\hline Role activities - emotional & $97.0 \pm 10.0$ & $-31.8 \pm 46.2^{*}$ & -3.17 & $100.0 \pm 0.0$ & $-15.1 \pm 31.1$ & \# \\
\hline Bodily pain & $95.7 \pm 10.5$ & $-19.8 \pm 23.8^{*}$ & -1.89 & $89.3 \pm 14.6$ & $-5.6 \pm 16.0$ & -0.38 \\
\hline General health perception & $82.3 \pm 13.3$ & $-0.9 \pm 18.7$ & -0.07 & $83.2 \pm 14.7$ & $1.4 \pm 9.8$ & 0.09 \\
\hline Last year's health change & $56.8 \pm 16.2$ & $-13.6 \pm 25.9$ & -0.84 & $58.3 \pm 12.3$ & $-4.2 \pm 20.9$ & -0.34 \\
\hline
\end{tabular}

${ }^{a}$ Initial mean MOS-SF36 score \pm SD, using scale of 0 (worst health) to 100 (best health). ${ }^{\mathrm{b}}$ Mean change MOS-SF36 score \pm SD. ${ }^{\mathrm{c}}$ ES is defined as effect size calculated as mean change score per group divided by the standard deviation of the initial mean score in that group. A positive effect size denotes improvement, a negative effect size denotes worsening. ${ }^{*}$ Could not be calculated. ${ }^{*} \mathrm{p}<0.05,{ }^{* *} \mathrm{p}<$ 0.005 .

Table 4. Circadian parameters: core body temperature and DLMO

\begin{tabular}{|c|c|c|c|c|c|c|c|c|}
\hline & \multicolumn{4}{|c|}{ Recipients } & \multicolumn{4}{|c|}{ Donors } \\
\hline & $\mathrm{n}$ & baseline & $\begin{array}{l}3 \text { months after } \\
\text { transplantation }\end{array}$ & $\mathrm{p}$ value & $\mathrm{n}$ & baseline & $\begin{array}{l}3 \text { months after } \\
\text { transplantation }\end{array}$ & $\mathrm{p}$ value \\
\hline Time of cBT, h & 12 & $2: 42 \pm 2: 08$ & $1: 44 \pm 2: 59$ & 0.31 & 13 & $1: 51 \pm 4: 55$ & $3: 52 \pm 3: 34$ & 0.24 \\
\hline DLMO, h & 11 & $22: 18 \pm 1: 05$ & $21: 44 \pm 1: 15$ & 0.24 & 16 & $22: 21 \pm 1: 15$ & $22: 03 \pm 1: 24$ & 0.28 \\
\hline
\end{tabular}

Data are expressed as mean $\pm \mathrm{SD} . \mathrm{DLMO}=$ Dim light melatonin onset; $\mathrm{cBT}=$ core body temperature.

Circadian Rhythm in Kidney

Transplantation 
short time span after transplantation that was allowed for the final assessment. In addition, these transplant recipients probably were in relatively good condition prior to transplantation as compared to previously studied hemodialysis patients because $57 \%$ of our analyzed transplantations were performed preemptively. Indeed, hemodialysis treatment has been identified as one of the predictors of poor pre-transplantation sleep quality [37].

Quality of life improved with the recipients 3 months after renal transplantation, as expected. Obviously, it is not possible to conclude that this is related to an improvement in circadian rhythmicity of melatonin, sleep, or blood pressure since we did not find any changes in these parameters.

As could be expected, kidney donation had short-term negative influences on the quality of life. Previously, several small prospective studies have already shown decreases in SF-36 scores shortly after donation [38]. These are likely to be temporary changes since larger, long-term retrospective studies on quality-of-life changes of kidney donors reported scores to be equal to or better than nondonor controls $[39,40]$. The larger negative effect sizes with open versus laparoscopic nephrectomy, possibly point to a more favorable quality-of-life course with laparoscopic nephrectomy.

In conclusion, we did not find an improvement of nighttime melatonin secretion, blood pressure dipping, DLMO and body temperature correlation, sleep onset, total sleep time, and sleep efficiency with kidney transplantation. The number of nighttime wake minutes after initial sleep onset improved after transplantation. However, subjective judgments of quality of life improved just as the as daytime sleepiness scores. It should be noted that daytime sleepiness scores were already within the reference range before transplantation. These subjective improvements could not be related to a better function of circadian rhythmicity. Future research should focus on the long-term effects of kidney transplantation on melatonin and sleep in larger groups of transplant recipients with a longer history of renal disease.

\section{Acknowledgments}

We thank Hiske Wellink, Yvonne de Koter, Carla Schrauwers, and Marjon van Vliet for their assistance with inclusions of participants and collecting data and Pieternel Pasker-de Jong for her careful review of the manuscript.

\section{Trial Registry}

Netherlands Trial Registry (www.trialregister.nl).

\section{Registration Number}

NTR2974.

\section{Authors' Contributions and Funding Sources}

M. Russcher participated in the study concept and design, acquisition of data, analysis and interpretation of data, and writing of the article. Forms of support received: none. No conflict of interest.

J.E. Nagtegaal participated in the study concept and design, acquisition of data and revising the article. Forms of support received: none. No conflict of interest.

S.A. Nurmohamed participated in acquisition of data and revising the article. Forms of support received: none. No conflict of interest.

B.C.P. Koch participated in the study concept and design and revising of the article. Forms of support received: none. No conflict of interest.

M.M.L. van der Westerlaken participated in material support and revising of the article. Forms of support received: none. No conflict of interest.

E.J.W. van Someren participated in analysis of data and revising of the article. Forms of support received: none. No conflict of interest.

S.J.L. Bakker participated in analysis of data, critically revising and rewriting of the article. Forms of support received: none. No conflict of interest.

P.M. ter Wee participated in the study concept and design, material support, revising of the article and study supervision. Forms of support received: none. No conflict of interest.

C.A.J.M. Gaillard participated in the study concept and design, interpretation of the data, material support, study supervision and writing of the article. Forms of support received: none. No conflict of interest.

\section{References}

1 Parker KP: Sleep disturbances in dialysis patients. Sleep Med Rev 2003;7:131-143.

-2 Parker KP, Bliwise DL, Bailey JL, Rye DB: Daytime sleepiness in stable hemodialysis patients. Am J Kidney Dis 2003;41:394402.

-3 Araujo SM, Bruin VM, Daher EF, Medeiros CA, Almeida GH, Bruin PF: Quality of sleep and day-time sleepiness in chronic hemodialysis: a study of 400 patients. Scand J Urol Nephrol 2011;45:359-364.

4 Araujo SM, de Bruin VM, Daher Ede F, Almeida GH, Medeiros CA, de Bruin PF: Risk factors for depressive symptoms in a large population on chronic hemodialysis. Int Urol Nephrol 2012;44:1229-1235.
Parker KP, Kutner NG, Bliwise DL, Bailey JL, Rye DB: Nocturnal sleep, daytime sleepiness, and quality of life in stable patients on hemodialysis. Health Qual Life Outcomes 2003;1:68.

6 Vgontzas AN, Liao D, Pejovic S, Calhoun S, Karataraki M, Basta M, et al: Insomnia with short sleep duration and mortality: the Penn State cohort. Sleep 2010;33:1159-1164. 
7 Turek NF, Ricardo AC, Lash JP: Sleep disturbances as nontraditional risk factors for development and progression of CKD: review of the evidence. Am J Kidney Dis 2012;60:823-833.

8 Arendt J: Melatonin: characteristics, concerns, and prospects. J Biol Rhythms 2005;20: 291-303.

-9 Claustrat B, Brun J, Chazot G: The basic physiology and pathophysiology of melatonin. Sleep Med Rev 2005;9:11-24.

10 Arendt J: Melatonin and human rhythms. Chronobiol Int 2006;23:21-37.

11 Brzezinski A: Melatonin in humans. N Engl J Med 1997;336:186-195.

-12 Karasek M, Szuflet A, Chrzanowski W, Zylinska K, Swietoslawski J: Decreased melatonin nocturnal concentrations in hemodialyzed patients. Neuro Endocrinol Lett 2005;26:653656.

13 Karasek M, Szuflet A, Chrzanowski W, Zylinska K, Swietoslawski J: Circadian serum melatonin profiles in patients suffering from chronic renal failure. Neuro Endocrinol Lett 2002;23(suppl 1):97-102.

14 Koch BC, van der Putten K, Van Someren EJ, Wielders JP, Ter Wee PM, Nagtegaal JE, et al: Impairment of endogenous melatonin rhythm is related to the degree of chronic kidney disease (CREAM study). Nephrol Dia Transplant 2010;25:513-519.

15 Russcher M, Koch BC, Nagtegaal JE, van Ittersum FJ, Pasker-de Jong PC, Hagen EC, et al: Long-term effects of melatonin on quality of life and sleep in haemodialysis patients (Melody study): a randomized controlled trial. Br J Clin Pharmacol 2013;76:668-679.

16 Buxton OM, Cain SW, O'Connor SP, Porter JH, Duffy JF, Wang W, et al: Adverse metabolic consequences in humans of prolonged sleep restriction combined with circadian disruption. Sci Transl Med 2012;4:129ra43.

17 Boggia J, Li Y, Thijs L, Hansen TW, Kikuya M, Björklund-Bodegård $\mathrm{K}$, et al: Prognostic accuracy of day versus night ambulatory blood pressure: a cohort study. Lancet 2007;370: 1219-1229.

18 Covic A, Gusbeth-Tatomir P, Mardare N, Buhaescu I, Goldsmith DJ: Dynamics of the circadian blood pressure profiles after renal transplantation. Transplantation 2005;80: 1168-1173.
19 Katz ME, Margulis F, Schiavelli R, Arias P, Head GA, Golombek DA: Disruption of transitional stages in 24-h blood pressure recording in renal transplant recipients. Front Neurol 2012;3:35

20 Jonas M, Garfinkel D, Zisapel N, Laudon M, Grossman E: Impaired nocturnal melatonin secretion in non-dipper hypertensive patients. Blood Press 2003;12:19-24.

21 Russcher M, Koch BCP, Gaillard CAJM, Nagtegaal JE, Ter Wee PM: Endogenous melatonin rhythm before and after kidney transplantation. ASN Kidney Week Abstr 2009;SAPO3109.

22 Goto N, Uchida K, Morozumi K, Ueki T, Matsuoka S, Katayama A, et al: Circadian blood pressure rhythm is disturbed by nephrectomy. Hypertens Res 2005;28:301-306.

23 Koch BC, Nagtegaal JE, Hagen EC, van der Westerlaken MM, Boringa JB, Kerkhof GA, et al: The effects of melatonin on sleep-wake rhythm of daytime haemodialysis patients: a randomized, placebo-controlled, cross-over study (EMSCAP study). Br J Clin Pharmacol 2009;67:68-75.

24 Morgenthaler T, Alessi C, Friedman L, Owens J, Kapur V, Boehlecke B, et al: Practice parameters for the use of actigraphy in the assessment of sleep and sleep disorders: an update for 2007. Sleep 2007;30:519-529.

25 Van der Zee KI, Sanderman R: Het meten van de algemene gezondheidstoestand met de RAND-36: een handleiding [Measurement of general health with the RAND-36: a manual]. Groningen: Noordelijk Centrum voor Gezondheidsvraagstukken, NCG, 1993.

26 Fagard R, Brguljan J, Thijs L, Staessen J: Prediction of the actual awake and asleep blood pressures by various methods of $24 \mathrm{~h}$ pressure analysis. J Hypertens 1996;14:557563.

27 McKenzie JE, Osgood DW: Validation of a new telemetric core temperature monitor. Therm Biol 2004;29:605-611.

28 Kazis LE, Anderson JJ, Meenan RF: Effect sizes for interpreting changes in health status. Med Care 1989;27:S178-S189.

29 Benloucif S, Burgess HJ, Klerman EB, Lewy AJ, Middleton B, Murphy PJ, et al: Measuring melatonin in humans. J Clin Sleep Med 2008; 4:66-69.
30 Lack LC, Gradisar M, Van Someren EJ, Wright HR, Lushington K: The relationship between insomnia and body temperatures. Sleep Med Rev 2008;12:307-317.

- 31 Van Someren EJ, Nagtegaal E: Improving melatonin circadian phase estimates. Sleep Med 2007;8:590-601.

32 Mahlberg R, Kienast T, Hädel S, Heidenreich JO, Schmitz S, Kunz D: Degree of pineal calcification (DOC) is associated with polysomnographic sleep measures in primary insomnia patients. Sleep Med 2009;10:439-445.

33 Kunz D, Schmitz S, Mahlberg R, Mohr A, Stöter C, Wolf KJ, et al: A new concept for melatonin deficit: on pineal calcification and melatonin excretion. Neuropsychopharmacology 1999;21:765-772.

-34 Nishizawa Y, Jono S, Ishimura E, Shioi A: Hyperphosphatemia and vascular calcification in end-stage renal disease. J Ren Nutr 2005; 15 : 178-182.

35 Koch BC, Hagen EC, Nagtegaal JE, Boringa JB, Kerkhof GA, Ter Wee PM: Effects of nocturnal hemodialysis on melatonin rhythm and sleep-wake behavior: an uncontrolled trial. Am J Kidney Dis 2009;53:658-664

36 Koch BC, Wosten YBM, Nagtegaal JE, Kerkhof GA, Wee PM: Prescription of hypnotics and potentially sleep-disturbing medication in haemodialysis patients Objective. PW Wet Platf 2008:2:132-135.

37 Rodrigue JR, Mandelbrot DA, Hanto DW Johnson SR, Karp SJ, Pavlakis M: A cross-sectional study of fatigue and sleep quality before and after kidney transplantation. Clin Transplant 2011;25:E13-E21.

38 Andersen MH, Mathisen L, Veenstra M, Oyen O, Edwin B, Digernes R, et al: Quality of life after randomization to laparoscopic versus open living donor nephrectomy: longterm follow-up. Transplantation 2007;84:6469.

39 Mjøen G, Stavem K, Westlie L, Midtvedt K, Fauchald P, Norby G, et al: Quality of life in kidney donors. Am J Transplant 2011;11 1315-1319.

40 Clemens K, Boudville N, Dew MA, Geddes C Gill JS, Jassal V, et al: The long-term quality of life of living kidney donors: a multicenter cohort study. Am J Transplant 2011;11:463469 .
Circadian Rhythm in Kidney

Transplantation 